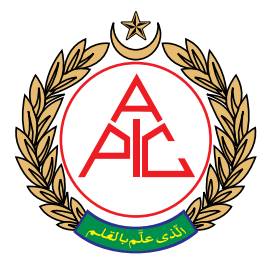

${ }^{1}$ Consultant Anesthesiologist, King Faisal Specialist Hospital and Research Centre, Riyadh, (Saudi Arabia)

Correspondence: $\mathrm{Dr}$

Amer Majeed, Consultant Anesthesiologist, King Faisal Specialist Hospital and Research Centre, Zahrawi St, Al Maather، Al Maazer, Riyadh 12713, , (Saudi Arabia),

E-mail: amer.majeed@gmail.com

Received: 4 March 2020;

Reviewed \& Accepted: 6

March 2020

\section{Is hemoglobin the missing link in the pathogenesis of COVID-19?}

\author{
Amer Majeed, FCARCSI, FRCA, FFICM ${ }^{1}$, \\ Matloob Ashraf Shajar, FRCA, FFICM ${ }^{1}$
}

\begin{abstract}
This editorial considers studies which establish our current understanding of SARSCoV-2 and the indicated direction for treatment of COVID-19 patients and future research. Recent modelling studies point to the effect of SARS-CoV-2 on hemoglobin as a key element in understanding the pathogenesis of COVID-19. This would suggest that the focus of treatment of COVID-19 would need to shift towards maintaining the oxygen carrying capacity of blood; potentially with blood transfusions and superoxygenation, perhaps including hyperbaric oxygen therapy. Further, early prevention of thromboembolism, and suppression of the immune response due to hemoglobin damage, may help contain the clinical course.
\end{abstract}

Key words: Corona virus disease; COVID-19; SARS-CoV-2; ARDS; Hemoglobin

Citation: Majeed A, Shajar MA. Is hemoglobin the missing link in the pathogenesis of COVID-19? Anaesth pain intensive care 2020;24(1):9-12. DOI: https://doi.org/10.35975/apic.v24i1.1216

\section{INTRODUCTION}

On 31st December 2019, Chinese authorities reported to the World Health Organization (WHO) a cluster of cases of unexplained pneumonia. On $7^{\text {th }}$ January 2020, these cases were confirmed to have been caused by a novel coronavirus, later classified as Severe Acute Respiratory Syndrome Coronavirus 2 (SARS-CoV-2). The WHO termed the resulting disease coronavirus disease 2019 (COVID-19) and declared it to be a pandemic on $12^{\text {th }}$ March 2020. At the time of writing this editorial, with almost 2 million diagnoses and 0.1 million lives claimed, many healthcare systems around the world are struggling to cope with the associated exponential rise in hospitalization. Daily life has come to a crippling halt in several countries as worldwide governments attempt to curtail spread of SARS-CoV-2 using methods such as social distancing, nationwide lockdowns and curfews. As massive global research effort continues and new data continue to be generated, our understanding of COVID-19 evolves by each passing day.

\section{Core Research on SARS-CoV-2 and COVID-19:}

Phylogenetic network analysis of SARS-CoV-2 genomes has demonstrated existence of several mutant variants, mainly categorized into types $A$ to $C$, with type B mostly endemic in East Asia, and A \& $C$ in the rest of the world. ${ }^{1}$ Rapidly emerging data from several centers suggests variation in transmission, virulence, disease spectrum, and the mortality rate. ${ }^{2,3,4,5,6,7}$ The role of angiotensin converting enzyme receptor type 2 (ACE2) as the primary binding site for SARS-CoV-2 for gaining entry into the cell has been elucidated, ${ }^{8}$ and interestingly, variations in the genetic makeup of this receptor has been suggested to partially explain lower susceptibility of some populations to COVID-19. ${ }^{9}$

Huang, et al. ${ }^{3}$ described the chief symptoms of COVID-19 as: fever (98\%), cough (76\%), and myalgia or fatigue (44\%). Less common symptoms were noted to be: sputum production (28\%), headache $(8 \%)$, hemoptysis (5\%), and diarrhea (3\%). Dyspnea developed in $55 \%$ of COVID-19 patients; $63 \%$ had lymphopenia. All patients presented with pneumonia and abnormal findings on chest CT scan. Frequent complications were noted to include: acute respiratory distress syndrome (ARDS) (29\%), RNAemia (15\%), acute cardiac injury (12\%), and secondary infection $(10 \%)$. Admission to an ICU was needed by $32 \%$ of COVID-19 patients; $15 \%$ of the patients did not 
survive. Similar incidences were confirmed in several studies. ${ }^{4,5}$

The severity of COVID-19 in confirmed cases ranged from mild to critical. ${ }^{5}$ Mild disease was reported in $81 \%$ of cases (no or mild pneumonia), severe in $14 \%$ of cases (i.e. with dyspnea, hypoxia, or $>50 \%$ lung involvement on imaging within 24 to $48 \mathrm{~h}$ ), and critical in $5 \%$ (i.e. with respiratory failure, shock, or multi-organ dysfunction).

Zhou, et al. identified laboratory features associated with adverse outcomes, including: lymphopenia, raised liver enzymes, lactate dehydrogenase (LDH), inflammatory markers (e.g. C-reactive protein [CRP], ferritin), D-dimers ( $>1 \mu \mathrm{g} / \mathrm{mL})$, prothrombin time (PT), troponin, and creatine phosphokinase (CPK). ${ }^{6}$ These point to an excessive inflammatory response in COVID-19 associated with critical and fatal illnesses. ${ }^{10}$

\section{Areas requiring further evidence:}

Initial reports of harm caused by non-steroidal antiinflammatory drugs (NSAIDs) in COVID-19 led to recommendations from several bodies to avoid immunosuppression (e.g. with corticosteroids / NSAIDs); clinical experience reported by several centers controverts this recommendation. ${ }^{11}$ Two distinct phases of immune response are observed in this disease. Good state of general health and appropriate genetic background [e.g. some human leucocyte antigen (HLA) - types may offer specific antiviral immunity] may prevent progression from mild / moderate to severe disease form; the preventive immune failure plinths viral spread and destruction of the affected tissues. Inflammation in the lungs is the main cause of life-threatening respiratory disorders at the severe stage, and efforts directed at suppressing inflammation may help to manage the symptoms. ${ }^{12}$

ARDS consequent upon the lung damage, not less than the other systems, in these patients has baffled the intensivists. The near normal respiratory system compliance in the presence of severe hypoxemia is not synchronous with the typical ARDS picture.

Gattinoni, et al. in their landmark editorial, ${ }^{7}$ proposed two clinical phenotypes; type L (low elastance) and type $\mathrm{H}$ (high elastance). Type $\mathrm{L}$ has been found in $70 \%$ of patients, and there is dissociation between their relatively well preserved lung mechanics and the severity of hypoxemia (high compliance, with ventilation / perfusion or V/Q mismatch); therefore, there is a limited response to PEEP. In contrast, type $\mathrm{H}$ (30\% of patients) present with a typical ARDS picture. Progression from type $\mathrm{L}$ to $\mathrm{H}$ is possible, and treatment requires adjustment accordingly. The exact mechanism of the disparity between the two presentations still remains uncertain; hypoxic pulmonary vasoconstriction and thromboembolism may explain the $\mathrm{L}$ type, whereas inflammatory lung infiltration augmented by excessive negative intrathoracic pressure in spontaneously breathing patient may elucidate the $\mathrm{H}$ type.

There are reports of underlying thromboembolic disease emerging from post-mortem studies. ${ }^{13,14}$ Microthrombosis leading to the dysregulated pulmonary perfusion may possibly clarify the $\mathrm{V} / \mathrm{Q}$ mismatch and hypoxaemia associated with the phenotype type $\mathrm{L}$ described above. It may also explicate the conflicting reports about the extent and mechanism of acute kidney injury, ${ }^{15,16}$ and acute liver injury. ${ }^{17}$ The alarming level of cardiomyopathy, arrhythmias, acute cardiac injury and shock in COVID-19 may also find its roots there. ${ }^{4,18,19}$

ACE2 receptors, which are present in the outer surface of cells in the lungs, arteries, heart, kidneys, and intestines, serve as the entry portal of SARS-CoV-2 into cells. ${ }^{8}$ Ubiquitous presence of these receptors in these organ systems has been considered as the key to pathogenesis of COVID-19, but still there are unanswered questions due to conflicting evidence. For instance, on one hand, the possible upregulation of ACE2 leads to an increased risk of infection of the pulmonary (and possibly other) tissues, and on the other hand there is evidence to existence of both cardio protective and pulmonary protective activity of ACE2. ${ }^{20}$ Concerns have been raised regarding concomitant use of ACE1 Inhibitors in COVID-19, due to the anticipated upregulatory effect on ACE2 receptors, potentiating entry portals for SARS-CoV-2. However, discontinuing medicated inhibitors in the patients already taking them has not been supported by various specialist bodies, due to lack of evidence of harm, but more so due to reported protective effect of these agents against lung injury. ${ }^{21,22}$

\section{COVID-19 and hemoglobin: the missing link?}

Interestingly, a study by Wenzhong, et al. could provide the missing link in the understanding of the pathogenesis of COVID-19. ${ }^{23}$ Through conserved domain analysis, homology modelling, and molecular docking, they compared the biological roles of certain proteins of the novel coronavirus. Their results showed that these proteins, binding to porphyrin, could attack the 1-beta chain of hemoglobin to dissociate iron and form porphyrin (hemoglobin consists of hem and globin; hem is composed of iron and porphyrin).

The attack would result in a drop in hemoglobin available to carry oxygen and also shift the oxygen dissociation curve and reduce the oxygen affinity with hemoglobin (thus producing a picture similar to methemoglobinemia, or carbon monoxide poisoning). The lung cells would have extremely intense inflammatory response and poisoning due to the ensuing inability to exchange carbon dioxide 
and oxygen efficiently, which eventually would result in ground-glass appearance on lung images. The mechanism would also interfere with the normal hem anabolic pathway of the human body and would result in human disease.

According to the validation analysis of these findings, chloroquine could prevent SARS-CoV-2 proteins from attacking hem and forming porphyrin, and also inhibit their ability to bind to porphyrins to a certain extent, effectively relieving the symptoms of respiratory distress. Favipiravir could also inhibit some of these proteins from binding to porphyrin, thus preventing the virus from entering host cells and catching free porphyrins.

\section{CONCLUSION}

In summary, majority of the patients progressing to the severe form of COVID-19 present with hypoxia with well-preserved lung mechanics, but ARDS like picture on chest imaging. They may require unconventional therapeutic interventions, different from the classic ARDS management, thus avoiding the use of high PEEP or PEEP/FiO ${ }_{2}$ scale, and shift focus of treatment towards oxygenation, reducing the V/Q mismatch (prone positioning, partial anti coagulation, inhaled prostaglandins, nitric oxide), and maintaining the oxygen carrying capacity of blood (blood transfusions, super-oxygenation). Corticosteroids, judicious fluid management, and prevention of barotrauma, may slow progression of the disease to classic ARDS. In deed there is a great potential of further research in this direction, and we might have to wait for a solid evidence-based management protocol.

Conflict of interest: None declared by the author

\section{REFERENCES}

1. Forster P, Forsterd L, Renfrew C, Forsterc M. Phylogenetic network analysis of SARS-CoV-2 genomes. Proc Natl Acad Sci U S A. 2020 Apr 8. pii: 202004999. [PubMed] [Free Full Text] D0I: $10.1073 /$ pnas.2004999117

2. Tang X, Wu C, Li X, Song Y, Yao X, Wu $X$, et al. On the origin and continuing evolution of SARS-CoV-2. Natl Sci Rev. 2020 Mar 3 [PubMed] DOI: 10.1093/ nsr/nwaa036

3. Huang $C$, Wang $Y$, Li X, Ren L, Zhao $\mathrm{J}, \mathrm{Hu} \mathrm{Y}$, et al. Clinical features of patients infected with 2019 novel coronavirus in Wuhan, China. Lancet. 2020;395(10223):497506. [PubMed] DOI: https://doi. org/10.1016/S0140-6736(20)30183$\underline{5}$

4. Wang D, Hu B, Hu C, Zhu F, Liu X, Zhang J, et al. Clinical Characteristics of 138 Hospitalized Patients With 2019 Novel Coronavirus-Infected Pneumonia in Wuhan, China. JAMA, 2020 Feb 7. [PubMed] [Free Full Text] DOI: 10.1001/jama.2020.1585

5. Wu Z, McGoogan JM. Characteristics of and Important Lessons from the Coronavirus Disease 2019 (COVID-19) Outbreak in China: Summary of a Report of 72314 Cases from the Chinese Center for Disease Control and Prevention. JAMA, 2020 Feb 24. [PubMed] [Free Full Text] DOI: 10.1001/jama.2020.2648.

6. Zhou F, Yu T, Du R, et al. Clinical course and risk factors for mortality of adult inpatients with COVID-19 in Wuhan, China: a retrospective cohort study. Lancet. 2020; 395(10229):1054. [PubMed] [Free Full Text] DOI: $10.1001 /$ jama.2020.2648

7. Gattinoni L, Chiumello D, Caironi P, Busana M, Romitti F, Brazzi L, et al. COVID-19 pneumonia: different respiratory treatment for different phenotypes? Intensive Care Med. 2020. (in press) [Free Full Text] DOI: $10.1007 / \mathrm{s} 00134-020-06033-2$

8. Zhou P, Yang X-L, Wang X-G, Hu $B$, Zhang L, Zhang $W$, et al. A pneumonia outbreak associated with a new coronavirus of probable bat origin. Nature. 2020 Mar;579(7798):270-273. [PubMed] [Free Full Text] DOI: 10.1038/s41586020-2012-7.

9. Hussain M, Jabeen N, Raza F, Shabbir $S$, Baig $A A$, Amanullah $A$, et al. Structural Variations in Human ACE2 may Influence its Binding with SARSCoV-2 Spike Protein. J Med Virol.
2020 Apr 6. DOI: $10.1002 /$ imv.25832.

10. Mehta P, McAuley DF, Brown M, Sanchez E, Tattersall RS, Manson JJ, et al. COVID-19: consider cytokine storm syndromes and immunosuppression. Lancet. 2020;395(10229):10331034. [PubMed] [Free Full Text] DOl: 10.1016/S0140-6736(20)30628-0

11. Russell B, Moss C, Rigg A, Van Hemelrijck M. COVID-19 and treatment with NSAIDs and corticosteroids: should we be limiting their use in the clinical setting? Ecancermedicalscience. 2020;14:1023. Published 2020 Mar 30. [PubMed] [Free Full Text] DOI: $10.3332 /$ ecancer.2020.1023

12. Shi $Y$, Wang, $Y$, Shao $C$, Huang J, Gan J, Huang X, et al. COVID-19 infection: the perspectives on immune responses. Cell Death Differ. 2020 Mar 23. [PubMed] DOI: $10.1038 / \mathrm{s} 41418-$ 020-0530-3

13. Danzi GB, Loffi M, Galeazzi G, Gherbesi E. Acute pulmonary embolism and COVID-19 pneumonia: a random association? Eur Heart J. 2020 Mar 30. [PubMed] DOI: 10.1093/eurhearti/ ehaa254

14. Xie $Y$, Wang $X$, Yang $P$, Zhang $S$. COVID-19 Complicated by Acute 
Pulmonary Embolism. Radiology: Cardiothoracic Imaging 2020 Mar 16; 2(2):e200067. [Free Full Text] DOI: $10.1148 /$ ryct.2020200067

15. Wang L, Li X, Chen H, Yan S, Li D, Li Y, et al. Coronavirus Disease 19 Infection Does Not Result in Acute Kidney Injury: An Analysis of 116 Hospitalized Patients from Wuhan, China. Am J Nephrol. 2020 Mar 31:1-6. [PubMed] [Free Full Text] DOI: $10.1159 / 000507471$

16. Pan $X, X u D$, Zhang $H$, Zhou W, Wang LH, Cui XG. Identification of a potential mechanism of acute kidney injury during the COVID-19 outbreak: a study based on single-cell transcriptome analysis. Intensive Care Med. 2020 Mar 31. [PubMed] [Free Full Text] DOI: 10.1007/s00134-020-06026-1

17. Zhang C, Shi L, Wang FS. Liver injury in COVID-19: management and challenges. Lancet Gastroenterol Hepatol. 2020;5(5):428-430. [PubMed] [FreeFull Text] D0I: $10.1016 /$ S2468-1253(20)30057-1

18. Shi S, Qin M, Shen B, Cai Y, Liu T, Yang $F$, et al. Association of cardiac injury with mortality in hospitalized patients with COVID-19 in Wuhan, China. JAMA Cardiol. 2020 Mar 25. [PubMed] [Free Full Text] DOI: 10.1001 /jamacardio.2020.0950

19. Arentz M, Yim E, Klaff L, Lokhandwala $S$, Riedo FX, Chong $M$, et al. Characteristics and Outcomes of 21 Critically III Patients With COVID-19 in Washington State. JAMA. 2020 Mar 19. [PubMed] [Free Full Text] DOI: 10.1001/jama.2020.4326

20. Caldeira D, Alarcão J, Vaz-Carneiro A, Costa J. Risk of pneumonia associated with use of angiotensin converting enzyme inhibitors and angiotensin receptor blockers: systematic review and meta-analysis. BMJ. $2012 \mathrm{Jul}$ 11;345:e4260 [PubMed] [Free Full Text] DOI: 10.1136/bmi.e4260.

21. HFSA/ACC/AHA Statement Addresses Concerns Re: Using RAAS Antagonists in COVID-19. American College of Cardiology (ACC). Accessed on: $8^{\text {th }}$ April 2020. Available at: https:// professional.heart.org/professional/ ScienceNews/UCM 505836 HFSAACCAHA-statementaddresses-concerns-re-using-RAASantagonists-in-COVID-19.jsp

22. Guo J, Huang Z, Lin L, LV J. Coronavirus disease 2019 and cardiovascular disease: a viewpoint on the potential influence of angiotensinconverting enzyme inhibitors/ 